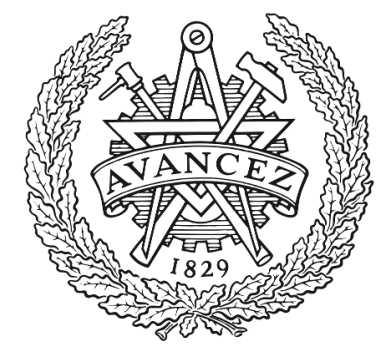

CHALMERS

UNIVERSITY OF TECHNOLOGY

\title{
Partial safety factors for the anchorage capacity of corroded reinforcement bars in concrete
}

Downloaded from: https://research.chalmers.se, 2023-04-26 08:59 UTC

Citation for the original published paper (version of record):

Blomfors, M., Larsson Ivanov, O., Honfi, D. et al (2019). Partial safety factors for the anchorage capacity of corroded reinforcement bars in concrete. Engineering Structures, 181: 579-588. http://dx.doi.org/10.1016/j.engstruct.2018.12.011

N.B. When citing this work, cite the original published paper. 


\title{
Partial safety factors for the anchorage capacity of corroded reinforcement bars in concrete
}

Authors: Mattias Blomfors* (Chalmers/RISE), Oskar Larsson Ivanov (Lund University), Dániel Honfí (RISE), Morten Engen (Multiconsult ASA/NTNU).

*Corresponding author: blomfors@chalmers.se, Sven Hultins gata 6, SE-412 96, Gothenburg, Sweden.

\begin{abstract}
Many reinforced concrete bridges in Europe and around the world are damaged by reinforcement corrosion and the annual maintenance costs are enormous. It is therefore important to develop reliable methods to assess the structural capacity of corroded reinforced concrete structures and avoid unnecessary maintenance costs. Although there are advanced models for determining the load carrying capacity of structures, it is not obvious how they should be used to verify the performance of existing structures. To confidently assess the bond of corroded reinforcement in concrete, for example, the calculation model must give a sufficient safety margin. When designing new structures, semi-probabilistic approaches (such as the partial safety factor method) are adopted to achieve the target reliabilities specified in structural design codes. This paper uses probabilistic methods to develop partial factors for application in an existing bond model, to assess the safety of corroded reinforced concrete structures. The response of the bond model was studied using Monte Carlo (MC) simulations for several design cases, with probability distributions fitted to the results. Partial factors were then derived, based on these distributions. Furthermore, an MC-based simulation technique called "importance sampling" was used to study the reliability of several deterministic bond assessments conducted using these partial factors. The results show that deterministic assessments which use the proposed partial factors lead to a safety level at least equal to the target value. The results presented in this paper will support the assessment of reinforced concrete structures with anchorage problems and give a reasonable approximation of the anchorage capacity with sufficient safety margin. When generalised to cover other failure modes and structural configurations, this will enable better utilisation of damaged structures and lead to major environmental and economical savings for society.
\end{abstract}

\section{INTRODUCTION}

Corroded reinforcement is the main cause of deterioration in reinforced concrete (RC) bridges today [1]. A report from the European research project BRIME, shows that one third of the bridges in the included countries suffer from corrosion damage [2]. The world cost of maintenance and repair of corrosion-damaged infrastructure is estimated at approximately $\$ 100$ billion per year [3]. Reliable methods of assessing structural capacity are of fundamental 
importance if we are to meet future demands on bridge stock, sustainably and without unnecessary strengthening and reconstruction.

In sound $\mathrm{RC}$, the reinforcement is protected by a passivating layer due to the alkalinity of the pore solutions. However, RC structures are exposed to the environment during their service life and the passivating layer can be broken down by such processes as carbonation of the concrete surrounding the reinforcement bars, or ingress of chloride ions into the pore solutions. Once the passivation is broken, the corrosion process can propagate [4]. The time to corrosion propagation depends on many factors, including the material and geometrical properties of the structure and the harshness of the surrounding environment. As the reinforcement bars corrode, there is also an increase in volume since the corrosion products occupy a greater volume than the steel they have consumed. Internal pressure builds up at the bond interface, which is equilibrated by tensile hoop stresses in the concrete. This can initially lead to increased bond strength. When the tensile stresses grow sufficiently large to crack the concrete, the confinement and thus also the bond strength is markedly reduced, as longitudinal cracks develop $[5,6]$.

The behaviour after the concrete cover is cracked depends on the amount of transverse reinforcement. A low stirrup content means a rapid decrease in the bond capacity with further corrosion, while for a high stirrup content it can be somewhat increased [7, 8, 9]. Corrosion influences RC structures in many ways on the sectional and structural levels. For an overview of the influence of corrosion on the structural behaviour, the reader is referred to [10]. This paper deals with the effect of corrosion on the anchorage capacity, to demonstrate the use of probabilistic assessment. It also highlights issues concerning the refinement of numerical models without proper considerations of safety aspects.

Bond in general and bond of corroded reinforcement in particular have been studied in several research projects, see $[11,12,13,14]$ for example. A simple assessment model for bond of corroded reinforcement has been developed [15] to make the results accessible and relevant to society. It is called ARC2010, with professional engineers as its intended users. The model solves the differential equation describing the force equilibrium between the reinforcement steel stress and the bond stress over a certain embedment length. An overview of the model is presented in Section 2.2.

For the model to be used in assessments of existing structures, it must be accompanied by a sufficient safety margin. This margin must be determined rationally and according to the reliability levels accepted by the engineering community. The main objective of this paper is to derive partial factors for the ARC2010 model, i.e. the assessment of corroded reinforcement, for use with the semi-probabilistic safety concept in Eurocode [16]. For the case of uncorroded reinforcement, cf. Mancini et al. work on reliability-based bond evaluation of tensed lapped joints or anchorages [17]. The availability to engineers of a calculation model which leads to an appropriate safety level will allow better assessment of corrosion-damaged RC structures. This, 
in turn, leads to major cost savings for society, because more of the inherent potential of existing infrastructure can be used and expensive strengthening and reconstruction can be avoided.

The paper consists of four main blocks, with the structure presented in Figure 1.

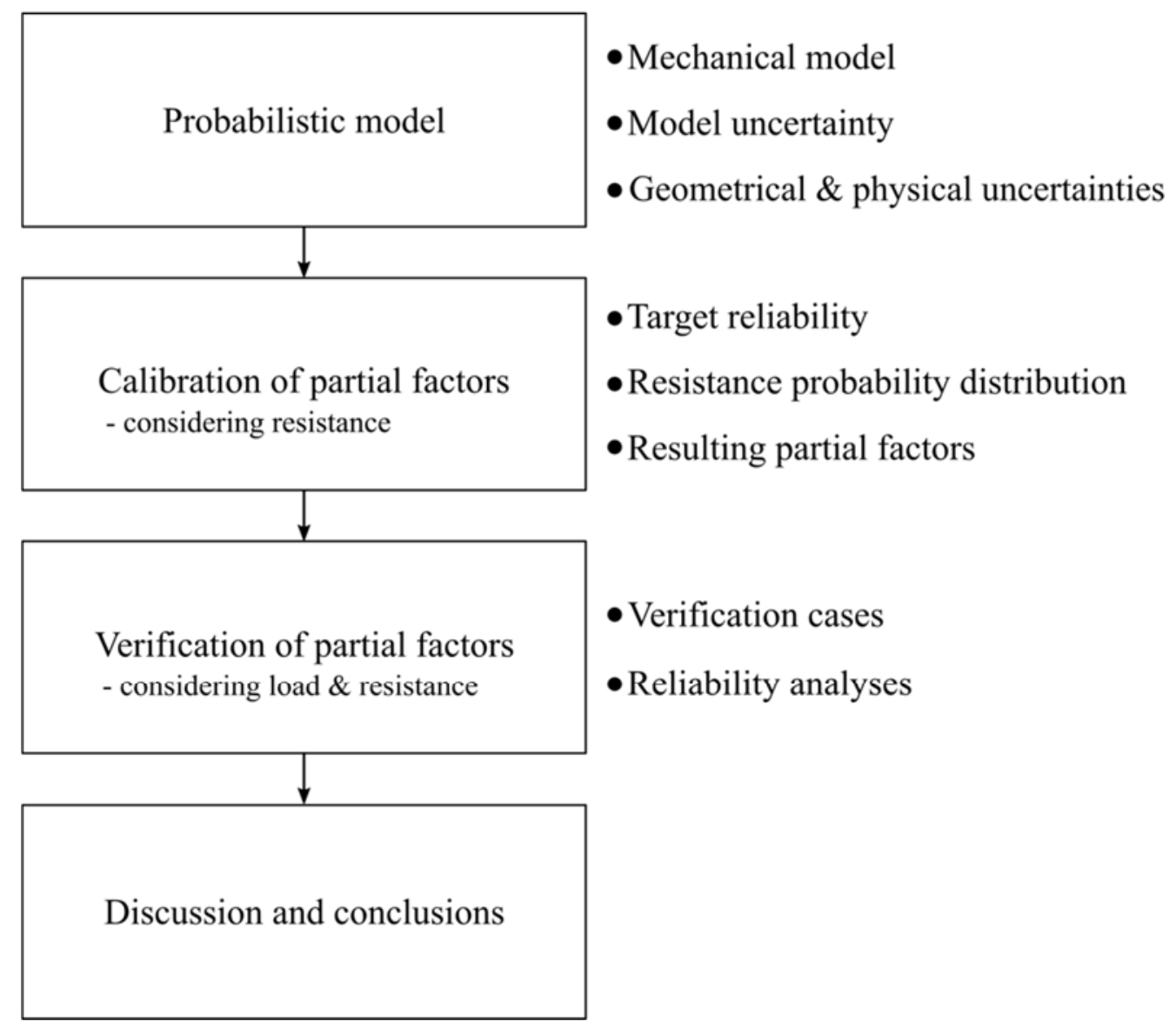

Figure 1: Flow chart describing the structure of the paper.

\section{PROBABILISTIC BOND MODEL FOR CAPACITY OF CORRODED REBARS}

\subsection{General}

In reality, all engineering models are associated with some level of uncertainty. In the context of structural models, it should be realised that the material and geometrical properties plus the calculation model itself are uncertain. The key difference between a deterministic analysis and a probabilistic analysis is that the input parameters (the basic variables) are not treated deterministic, but as random variables following some distributions. The basic variables comprise not only distributions of physical, geometrical and material quantities, but also parameters characterising the model itself [18]. 
The Joint Committee of Structural Safety (JCSS) [18] differentiates three main types of uncertainties:

- Intrinsic physical uncertainty.

- Parameter uncertainty.

- Model uncertainty.

Intrinsic physical uncertainty refers to the natural randomness of the property (the variability of concrete compressive strength, for example). The parameter uncertainty represents the statistical uncertainty related to the probabilistic description of the stochastic variables. A better understanding of the parameter distribution reduces this uncertainty (an increased number of data points used for inference, for example). The modelling uncertainty reflects the fact that the model gives an imperfect representation of the real structural behaviour, due to such factors as idealisations in the model, or lack of knowledge.

This section gives a brief presentation of the mechanical model, followed by the associated model uncertainty and, lastly, the physical and geometrical uncertainties.

\subsection{Mechanical model for anchorage capacity}

The ARC2010 model for calculating the anchorage capacity of corroded reinforcement bars is described in detail in [15]. The essence of the model is presented, because it is necessary to understand the calibration of partial factors presented later. The model is based on solving the equilibrium conditions along a reinforcement bar:

$\frac{\pi \phi_{\mathrm{m}}^{2}}{4} \cdot \frac{d \sigma_{\mathrm{s}}}{d x}-\pi \cdot \phi_{\mathrm{m}} \cdot \tau_{\mathrm{b}}=0$

where $\phi_{m}$ is the reinforcement diameter, $\sigma_{\mathrm{s}}$ is the stress in the reinforcement and $\tau_{\mathrm{b}}$ is the local bond stress. The reinforcement bar within the embedment length is assumed to be in the elastic range. Therefore, $\sigma_{\mathrm{s}}=E_{\mathrm{s}} \cdot \varepsilon_{\mathrm{s}}$ and $\varepsilon_{\mathrm{s}}=d u / d x$ where $E_{\mathrm{s}}$ is the elastic modulus, $\varepsilon_{\mathrm{s}}$ is the steel strain and $u$ is the displacement of the reinforcement bar. If the deformation of the concrete is neglected, the slip $s$ equals the displacement of the reinforcement bar. If a bar with embedment length $l_{\mathrm{b}}$ and prescribed displacement $u_{l_{\mathrm{b}}}$ is considered, the boundary conditions at the free and loaded end are, respectively:

$\sigma_{\mathrm{s}}(0)=0, \quad u\left(l_{\mathrm{b}}\right)=u_{l_{\mathrm{b}}}$

The differential equation can be solved numerically to obtain the steel stress and deformation along the bar, as well as the pull-out force and average bond stress over the embedment length.

The local bond stress $\tau_{\mathrm{b}}$ is defined by the local bond stress-slip relation, which for the uncorroded case is obtained from fib Model Code 2010 [19]. For corroded cases, the local bond stress-slip relation proposed in [15] is used instead. It is based on the fib Model Code 2010, but includes three modified and additional elements to account for the effect of corrosion: 
- Introduction of equivalent slip to account for bond degradation due to corrosion.

- Reduced confinement due to corrosion-induced cracking of the concrete cover.

- Modification of residual bond stress in case of low stirrup content, to avoid overly conservative results.

The reduction in capacity due to corrosion is accounted for by shifting the local bond-slip curve. In other words, an equivalent slip is added to the slip between steel and concrete. This can be expressed as:

$s_{\text {eff }}=s+s_{\text {eq }}$

where $s_{\text {eff }}$ is the effective slip, $s$ is the mechanical slip and $s_{\text {eq }}$ is the equivalent slip to account for the effect of corrosion. The minimum of the uncorroded local bond-slip curve and the shifted uncorroded curve forms the corroded curve. The concept of equivalent slip is presented in Figure 2.

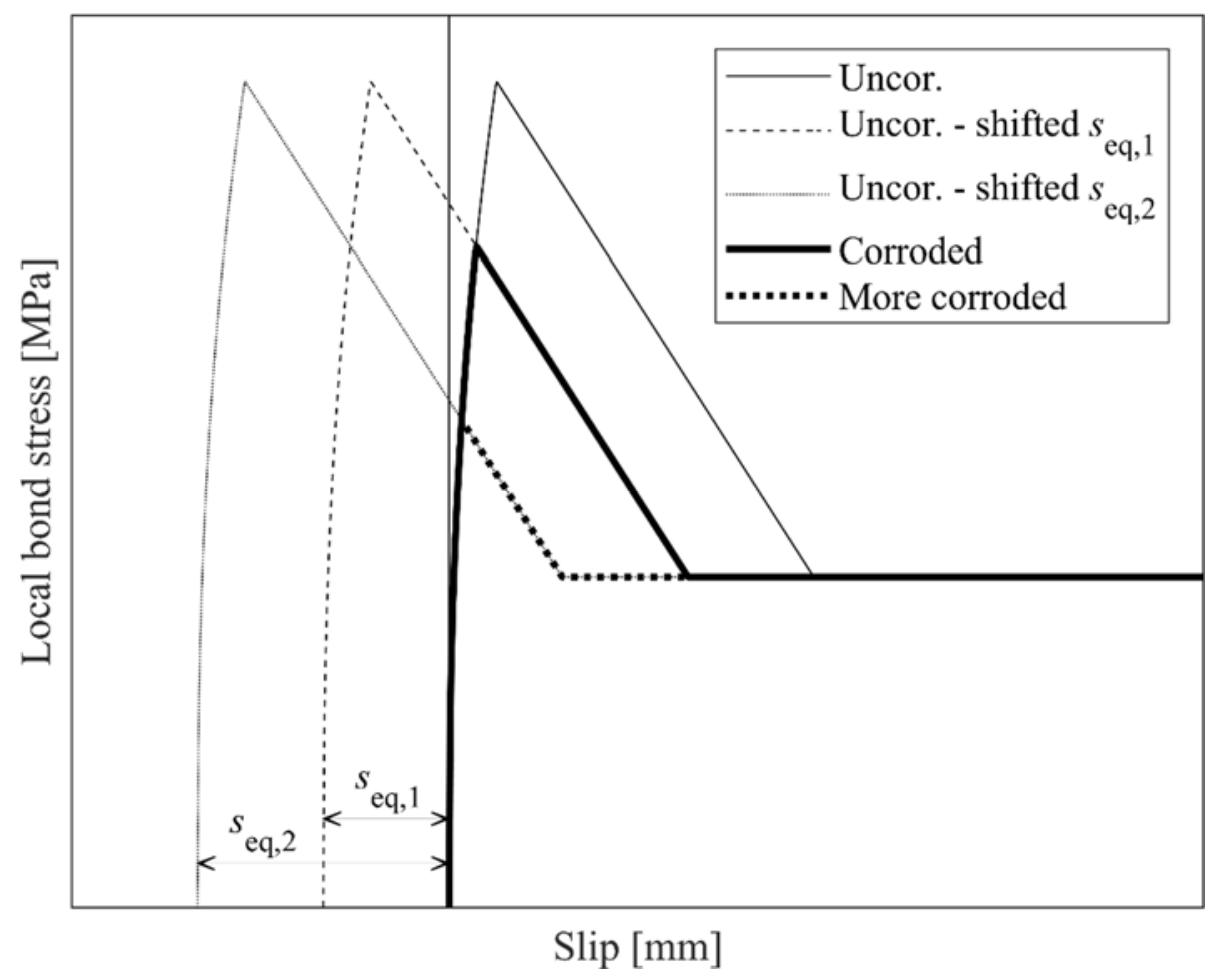

Figure 2: Illustration of the equivalent slip, $s_{\text {eq,1 }}<s_{\text {eq, }}$, to account for the effect of corrosion in a local bond stress-slip curve, where splitting strength governs the maximum bond stress.

The equivalent slips for cases with and without stirrups were calibrated against a large database of bond tests in [15], resulting in:

$$
\begin{aligned}
& s_{\text {eq,nostir }}=2.9 \cdot w_{\text {corr }} \\
& s_{\text {eq,stir }}=13.6 \cdot w_{\text {corr }}
\end{aligned}
$$


where $w_{\text {corr }}$ is the corrosion weight loss in decimals and $s_{\text {eq,(no)stir }}$ is the equivalent slip in mm. The corrosion domains for the model are $0-15 \%$ and $0-20 \%$ for cases without and with stirrups respectively. These are based on the validation of the model presented in [15].

The second modification to the original local bond stress-slip relation consists of reducing the confining effect of the concrete cover, when it is estimated to be cracked due to corrosion. The corrosion level causing cracking is estimated by an empirical expression, see [15]. The third modification in the local bond stress-slip relation for corroded reinforcement is a modification of the residual strength in case of low stirrup content. This is zero in fib Model Code 2010, which is considered too conservative so some remaining capacity is accounted for instead. For all details on the modifications and additions, the reader is referred to [15].

\subsection{Model uncertainty}

The resistance model uncertainty for uncorroded cases was assumed based on the recommendations of JCSS [18]. As information concerning anchorage failure is not given, a lognormal distribution with a mean value of 1 and a coefficient of variation (V) of 0.2 was chosen as a reference value for the uncorroded case. $V$ corresponds to the average between moment and shear failure. Note that the model uncertainty is dependent on the specific mechanical model used, and the domain of the input parameters c.f. $[17,20]$.

The bond capacities of specimens with corroded reinforcement typically show a large scatter. It is therefore of interest to quantify the resistance model uncertainty specifically for the ARC2010 model for corroded cases, since the uncertainty is believed to have significant impact on the probabilistic analyses. The resistance model uncertainty for corroded reinforcement was estimated by comparison to a database of more than 200 bond tests used to calibrate the model [15]. An approach similar to that of Engen et al. [20] was used, in which the modelling uncertainty was expressed as:

$\theta_{\mathrm{ARC}, i}=\left(R_{\mathrm{EXP}} / R_{\mathrm{ARC}}\right)_{i}$

where $R_{\mathrm{EXP}, i}$ is the resistance measured in the experiment and $R_{\mathrm{ARC}, i}$ is the resistance predicted by the ARC model. Two statistical distributions, normal and lognormal, were investigated for description of the modelling uncertainty $\theta_{\text {ARC }}$. A graphical examination, plus Lilliefors' test of normality [21] was used in the evaluation with the results are shown in Table 1. The acceptance criterion for the p-value was set to 0.05 .

Table 1: Summary of results from Lilliefors test of normality.

\begin{tabular}{|l|l|l|l|l|}
\hline \multirow{2}{*}{} & \multicolumn{2}{|c|}{ No stirrups } & \multicolumn{2}{c|}{ Stirrups } \\
\cline { 2 - 5 } & p-value & Conclusion & p-value & Conclusion \\
\hline$\theta \sim$ Normal & $<0.001<0.05$ & Reject & $0.004<0.05$ & Reject \\
\hline$\theta \sim$ Lognormal & $0.243>0.05$ & Do not reject & $0.197>0.05$ & Do not reject \\
\hline
\end{tabular}


It was concluded that a lognormal distribution represents the modelling uncertainty better than the normal distribution. The parameters for the distributions were estimated using Bayesian inference on the sample vector $\ln \theta_{\text {ARC }}$. A non-informative prior was used [22], since no previous information on the distribution was available. The resulting parameters are presented in Table 2, plus the final basic variables needed in the model.

Table 2: Basic variables related for the probabilistic model, where $\eta_{2}$ and $\alpha_{s}$ are parameters of the bond model elaborated on in [15].

\begin{tabular}{|l|l|l|l|l|l|l|}
\hline Parameter & $\mathbf{X}$ & Dist. & $\mu_{\mathbf{X}}$ & $\sigma_{\mathbf{X}}$ & $\mathrm{V}$ & Ref. \\
\hline $\begin{array}{l}\text { Resistance model uncertainty, } \\
\text { uncorroded [-] }\end{array}$ & $\theta_{\text {ARC,uc }}$ & Logn. & 1 & 0.20 & 0.20 & {$[18]$} \\
\hline $\begin{array}{l}\text { Resistance model uncertainty, } \\
\text { corroded without stirrups [-] }\end{array}$ & $\theta_{\text {ARC,c }}$ & Logn. & 1.14 & 0.58 & 0.51 & - \\
\hline $\begin{array}{l}\text { Resistance model uncertainty, } \\
\text { corroded with stirrups [-] }\end{array}$ & $\theta_{\text {ARC,c }}$ & Logn. & 0.86 & 0.38 & 0.45 & - \\
\hline Bond conditions [-] & $\eta_{2}$ & Det. & 1 & - & & {$[15]$} \\
\hline Shape of ascending branch [-] & $\alpha_{\mathrm{s}}$ & Det. & 0.4 & - & & {$[15]$} \\
\hline
\end{tabular}

It should be noted that for the corroded cases, the mean values of the resistance model uncertainty, $\theta_{\mathrm{ARC}, \mathrm{c}}$, differ from unity. This is because the model was originally calibrated against relative equivalent slip and not the absolute value of the bond strength. Consequently, the model makes a systematic error in predicting absolute strength. This is compensated for by $\theta_{\mathrm{ARC}, \mathrm{c}}$. It should further be noted that the modelling uncertainty also includes uncertainties related to the experimental tests in the database, e.g. measurements of bond strength, corrosion level and compressive strength etc.

\subsection{Geometric and physical uncertainty}

For the basic variables relating to the geometrical parameters, the distribution types and $\mathrm{V}$ were primarily obtained from JCSS probabilistic model code [18]. However, information about the distribution of some parameters was obtained elsewhere and others were assumed. For some geometrical parameters, the standard deviation was given rather than a $\mathrm{V}$ (for the spacing between stirrups, for example). This is because the deviation of the placement is not considered dependent on the mean spacing, as it would be if the same V were used for different spacing. A Gamma distribution was used to describe the concrete covers according to [23]. It was assumed that the spacing between the bars also followed this distribution. A uniform distribution was used for the clear spacing between the ribs of the reinforcement bars. The limits for the distribution were assumed, based on the provisions of standard SS-EN 10080 [24] plus in-house measurements. The standard deviation of the embedment length was assumed, rather than assigning a V. No information was found in the literature regarding the distribution of the average corrosion level. Furthermore, quantification of this parameter is not trivial and should 
probably be linked to some test method and the length of the anchorage region (elaborated upon in Section 5). A lognormal distribution was assumed in this study, since the corrosion levels are typically small but never negative.

Table 3 presents the basic variables relating to the geometry used in the probabilistic analyses. Several different mean values for the basic variables are used in the calibration in Section 3. They are therefore presented separately in Table 6 and Table 7 and not included here.

Table 3: Basic variables related to the geometry for probabilistic analyses.

\begin{tabular}{|l|l|l|l|l|l|}
\hline Parameter & $\mathbf{X}$ & Dist. & $\sigma_{\mathbf{X}}$ & $\mathrm{V}$ & Ref. \\
\hline Beam height [mm] & $h$ & Norm. & $4+0.006 \mu_{\mathbf{X}}$ & - & {$[18]$} \\
\hline Beam width [mm] & $w$ & Norm. & $4+0.006 \mu_{\mathbf{X}}$ & - & {$[18]$} \\
\hline Main bar diameter [mm] & $\phi_{\mathrm{m}}$ & Norm. & - & 0.01 & {$[18]$} \\
\hline Stirrup diameter [mm] & $\phi_{\mathrm{s}}$ & Norm. & - & 0.01 & {$[18]$} \\
\hline Stirrup spacing [mm] & $s_{\mathrm{t}}$ & Norm. & 10 & - & Assumption \\
\hline x-dir cover [mm] & $c_{\mathrm{x}}$ & Gam. & 10 & - & {$[18,23]$} \\
\hline y-dir cover [mm] & $c_{\mathrm{y}}$ & Gam. & 10 & - & {$[18,23]$} \\
\hline Clear bar spacing [mm] & $c_{\mathrm{s}}$ & Gam. & 10 & - & Assumption \\
\hline Clear rib spacing [mm] & $c_{\text {clear }}$ & Uni. & \multicolumn{1}{|l|}{ Interval: [0.3-0.6] $\phi_{\mathrm{m}}$} & Assumption \\
\hline $\begin{array}{l}\text { Anchorage Embedment } \\
\text { length [mm] }\end{array}$ & $l_{\mathrm{b}}$ & Norm. & 10 & - & Assumption \\
\hline Corrosion level [\%] & $w_{\text {corr }}$ & Logn. & - & 0.2 & Assumption \\
\hline
\end{tabular}

The basic material variables were obtained from JCSS [18]. A typical value applicable to different strength classes was used for the concrete cylinder strength. The V may seem slightly high compared to the results reported by, say, [25], but may be realistic in the case of a deteriorated structure. Furthermore, a sensitivity study by one of the authors [15] showed only a minor influence of Young's modulus on the anchorage capacity. A deterministic representation is therefore used for this variable. All the parameters that were considered appear in Table 4.

Table 4: Basic variables related to the materials for probabilistic analyses.

\begin{tabular}{|l|l|l|l|l|l|}
\hline Parameter & $\mathbf{X}$ & Dist. & $\sigma_{\mathbf{X}}$ & $\mathrm{V}$ & Ref. \\
\hline $\begin{array}{l}\text { Concrete cylinder } \\
\text { strength [MPa] }\end{array}$ & $f_{\mathrm{cm}}$ & Logn. & - & 0.17 & {$[18]$} \\
\hline Steel strength [MPa] & $f_{\mathrm{y}}$ & Logn. & $30 \mathrm{MPa}$ & $\sigma_{\mathbf{X}} /\left(f_{\mathrm{yk}}+2 \sigma_{\mathbf{X}}\right)$ & {$[18]$} \\
\hline $\begin{array}{l}\text { Young's modulus steel } \\
\text { [GPa] }\end{array}$ & $E_{\mathrm{s}}$ & Det. & - & - & Assumption \\
\hline
\end{tabular}




\section{CALIBRATION OF PARTIAL FACTORS}

\subsection{General}

In conventional ultimate limit state (ULS) design of concrete structures, according to the provisions in Eurocode [26, 27], the safety is verified using the partial factor method. The design is safe if the following condition is fulfilled:

$E_{\mathrm{d}}<R_{\mathrm{d}}$

where $E_{\mathrm{d}}$ is the design value for the load effect and $R_{\mathrm{d}}$ is the design value of the resistance. The following expression can be used for the design value of the resistance, in cases where the design values of the basic variables are not explicitly treated:

$R_{\mathrm{d}}=\frac{R_{\mathrm{k}}}{\gamma_{\mathrm{M}}}$

where $R_{\mathrm{k}}$ is the characteristic value of the resistance and $\gamma_{\mathrm{M}}$ is a partial factor including the modelling uncertainty and uncertainties in material properties. In this section, partial factors for the bond model for corroded reinforcement are calibrated so that the resulting design resistance has sufficient safety margin.

\subsection{Target reliability level}

Structures must meet the requirements imposed during their service life with an appropriate level of reliability [18]. In the context of reliability assessments, the term target reliability can be used to express the minimum acceptable safety margin for a structure. JCSS has made recommendations for target reliability, depending on the consequences of failure and relative cost of safety measures. These are based on cost-benefit analyses of simple but representative example structures. Table 5 presents the recommendations related to the ultimate limit state.

Table 5: Target reliabilities considering a one-year reference period recommended by JCSS [18].

\begin{tabular}{|l|l|l|l|}
\hline \multirow{2}{*}{$\begin{array}{l}\text { Relative cost of } \\
\text { safety measure }\end{array}$} & \multicolumn{3}{|l|}{ Consequences of failure } \\
\cline { 2 - 4 } & Minor & Moderate & Large \\
\hline Large & $\beta=3.1$ & $\beta=3.3$ & $\beta=3.7$ \\
\hline Normal & $\beta=3.7$ & $\beta=4.2$ & $\beta=4.4$ \\
\hline Small & $\beta=4.2$ & $\beta=4.4$ & $\beta=4.7$ \\
\hline
\end{tabular}

For existing structures (the main application area for the calculation model), the relative cost of safety measures is typically large. Moreover, major consequences may be expected in case of failure for bridges and other important infrastructure. This gives a target reliability index of $\beta_{1}=$ 3.7 for a one-year reference period. The one-year reference period has been selected to assess the reliability of a deteriorating structure in the final year of its working life [28]. Following the methods suggested in [28], this target reliability index could correspond to a bridge in 
Consequence Class 2 with a span $\leq 25 \mathrm{~m}$ or a building in Consequence Class 2 with a collapsed area $\leq 250 \mathrm{~m}^{2}$.

\subsection{Method for calibration of partial factors}

To find partial factors for the ARC model, the design resistance (corresponding to the target reliability) should be determined. This can be done if a distribution function for the resistance is available (the anchorage capacity, for example). The anchorage capacity may be written:

$R=\theta_{\mathrm{ARC}} R_{\mathrm{ARC}}(\boldsymbol{x})$

where $\boldsymbol{x}$ is a vector collecting the basic variables for the model. A nominal value for the resistance can be expressed as:

$R_{\mathrm{nom}}=\mu_{\theta_{\mathrm{ARC}}} R_{\mathrm{ARC}}\left(f_{\mathrm{ck}}, f_{\mathrm{yk}}, x_{\mathrm{nom}}\right)$

where $f_{\mathrm{ck}}$ and $f_{\mathrm{yk}}$ are the characteristic concrete and streel strength and $\boldsymbol{x}_{\mathrm{nom}}$ contains the nominal values of the other basic variables. The design value of the resistance $R_{\mathrm{d}}$ can be found from the resistance distribution according to:

$P\left[R \leq R_{\mathrm{d}}\right]=\Phi\left(-\alpha_{\mathrm{R}} \beta_{\mathrm{t}}\right)$

where $\Phi$ is the standard normal cumulative distribution function (CDF), $\alpha_{R}$ is a so-called sensitivity factor of the resistance (generally taken as 0.8 ) and $\beta_{\mathrm{t}}$ is the target reliability. The partial factors can be calculated as the ratio between the nominal and design resistance:

$\gamma_{\mathrm{R}}=\frac{R_{\mathrm{nom}}}{R_{\mathrm{d}}}=\frac{\mu_{\theta_{\mathrm{ARC}}} R_{\mathrm{ARC}}\left(f_{\mathrm{ck}}, f_{\mathrm{yk}}, x_{\mathrm{nom}}\right)}{R_{\mathrm{d}}}$

Consequently, the design resistance can be found using the partial factor according to:

$R_{\mathrm{d}}=\frac{R_{\mathrm{nom}}}{\gamma_{\mathrm{R}}}=\frac{R_{\mathrm{ARC}}\left(f_{\mathrm{ck}}, f_{\mathrm{yk}}, x_{\mathrm{nom}}\right)}{\gamma_{\mathrm{M}}}, \quad \gamma_{\mathrm{M}}=\frac{\gamma_{\mathrm{R}}}{\mu_{\theta_{\mathrm{ARC}}}}$

The distribution functions for the resistance $R$ (which make up the basis for calculating the partial factors), are obtained by fitting probabilistic distributions to results from numerical simulations. It is important to consider many different representative design cases for the simulations, as the partial factors only will be valid for the ranges of basic variables used for calibration. Several parameters were therefore varied in the analyses. These were selected based on a sensitivity study in a recent paper by the authors [29]. For the non-deterministic parameters, the levels refer to the mean value of the distributions and are presented in Table 6. The standard deviations of the parameters were obtained according to Table 2-Table 4. For the design case without stirrups, the basic variables related to the stirrups were simply excluded from the simulations.

Table 6: Parameter levels for the basic variables for the design cases.

\begin{tabular}{|l|l|l|l|l|l|l|l|}
\hline Parameter & $\mathbf{X}$ & Dist. & Lower & Upper & Intermediate & $\sigma_{\boldsymbol{X}}$ & V \\
\hline
\end{tabular}




\begin{tabular}{|l|l|l|l|l|l|l|l|}
\hline & & & $\begin{array}{l}\text { level } \\
\mu_{\mathbf{X}}\end{array}$ & $\begin{array}{l}\text { level } \\
\mu_{\mathbf{X}}\end{array}$ & level(s) & & \\
\hline $\begin{array}{l}\text { Main bar } \\
\text { diameter [mm] }\end{array}$ & $\phi_{\mathrm{m}}$ & Norm. & 16 & 25 & - & $\begin{array}{l}0.16 \mathrm{~mm} \\
0.25 \mathrm{~mm}\end{array}$ & 0.01 \\
\hline $\begin{array}{l}\text { Stirrup spacing } \\
\text { [mm] }\end{array}$ & $s_{\mathrm{t}}$ & Norm. & 100 & 260 & - & $10 \mathrm{~mm}$ & 0.10 \\
\hline $\begin{array}{l}\text { Concrete } \\
\text { strength [MPa] }\end{array}$ & $f_{\mathrm{cm}}$ & Logn. & 38 & 58 & - & $\begin{array}{l}6.35 \mathrm{MPa} \\
9.67 \mathrm{MPa}\end{array}$ & 0.17 \\
\hline $\begin{array}{l}\text { Effectiveness of } \\
\text { stirrups [-] }\end{array}$ & $k_{\mathrm{m}}$ & Det. & 0 & 12 & - & & \\
\hline $\begin{array}{l}\text { Number of bars } \\
\text { anchored [-] }\end{array}$ & $n \mathrm{~b}$ & Det. & 1 & 5 & - & & \\
\hline $\begin{array}{l}\text { Embedment } \\
\text { length [mm] }\end{array}$ & $l_{\mathrm{b}}$ & Norm. & 100 & 350 & 250 & $10 \mathrm{~mm}$ & 0.1 \\
\hline $\begin{array}{l}\text { Corrosion level } \\
\text { [\%] }\end{array}$ & $w_{\text {corr }}$ & Logn. & 0 & 20 & $5,10,15$ & $\begin{array}{l}0 \% \\
0 \%\end{array}$ & 0.03 \\
\hline & & & & & $\begin{array}{l}0.20 \\
1 \%\end{array}$ & \\
$2 \%$ & $3 \%$ & \\
\hline
\end{tabular}

Combining all parameter levels leads to a total of 480 design cases with stirrups. A similar combination, excluding the basic variables related to transverse reinforcement (such as stirrup spacing and effectiveness of stirrups), leads to 120 design cases.

The basic variables that were not changed between the design cases are summarised in Table 7 below. The clear rib spacing presented in Table 3 was used for all design cases, as well as the modelling uncertainties in Table 2 .

Table 7: Common basic variables for all design cases.

\begin{tabular}{|l|l|l|l|l|l|}
\hline Parameter & $\mathbf{X}$ & Dist. & $\mu_{\mathbf{X}}$ & $\sigma_{\boldsymbol{X}}$ & $\mathrm{V}$ \\
\hline Steel strength [MPa] & $f_{\mathrm{y}}$ & Logn. & 560 & 30 & 0.05 \\
\hline Young's modulus steel [GPa] & $E_{\mathrm{s}}$ & Det. & 200 & - & \\
\hline Stirrup diameter [mm] & $\phi_{\mathrm{s}}$ & Norm. & 10 & 0.1 & 0.01 \\
\hline x-dir cover [mm] & $c_{\mathrm{x}}$ & Gam. & 40 & 10 & 0.25 \\
\hline y-dir cover [mm] & $c_{y}$ & Gam. & 40 & 10 & 0.25 \\
\hline Clear bar spacing [mm] & $c_{\mathrm{s}}$ & Gam. & 55 & 10 & 0.18 \\
\hline
\end{tabular}

Monte Carlo (MC) simulations [30] were carried out using the chosen distributions to simulate the anchorage capacity of one bar in the cross-section belonging to the different design cases studied. The simulations were executed in MATLAB release 2016a [31] using the software framework UQlab [32]. The number of simulations was 10,000 for each design case, giving a total number of $6,000,000$ simulations. Latin hypercube sampling [33] was used to increase efficiency of the simulations. 
A verification was performed to see if the results from the simulations could be represented with lognormal distributions analogously to Section 2.3. Of the 480 design cases with stirrups, the Lilliefors' test ( $\mathrm{p}$-value acceptance criterion $<0.05$ ) rejected a lognormal distribution for 85 of them. For the cases without stirrups, a lognormal distribution was rejected for 50.

For the rejected cases, visual comparison and the Lilliefors' test were used to investigate whether a normal distribution could be a better representation for these cases. The conclusion of the analysis was that the lognormal distribution was the best of the common distributions to represent the data. The lognormal distribution is therefore used for all cases and is considered a reasonable approximation.

\subsection{Resulting partial factors}

The anchorage capacity can be represented by a lognormal distribution, as shown in Section 3.3, which makes the design resistance readily available as per Equation 11. The nominal capacity is obtained from a deterministic analysis using characteristic values for the concrete and steel strength and nominal values for the other basic variables. The partial factor $\gamma_{\mathrm{M}}$ is calculated using Equation 14.

Three probability density functions (pdf) for the resistance corresponding to three different embedment lengths are plotted in Figure 3, together the calculated with nominal and design values. All other parameters for the presented case are at their lower levels in Table 6 . The 5\%fractile characteristic values are also indicated. The figure clearly shows the difference between the nominal value of the resistance (calculated using the characteristic material strengths and nominal values of the rest of the basic variables) and the lower 5\%-fractile characteristic value of the resistance. The spread of the probability distributions may appear to differ among the embedment lengths shown in Figure 3. However, V, the design-to-nominal value ratio and the characteristic-to-nominal value ratio is similar for all three embedment lengths $(0.2,0.5$ and 0.7 respectively). 


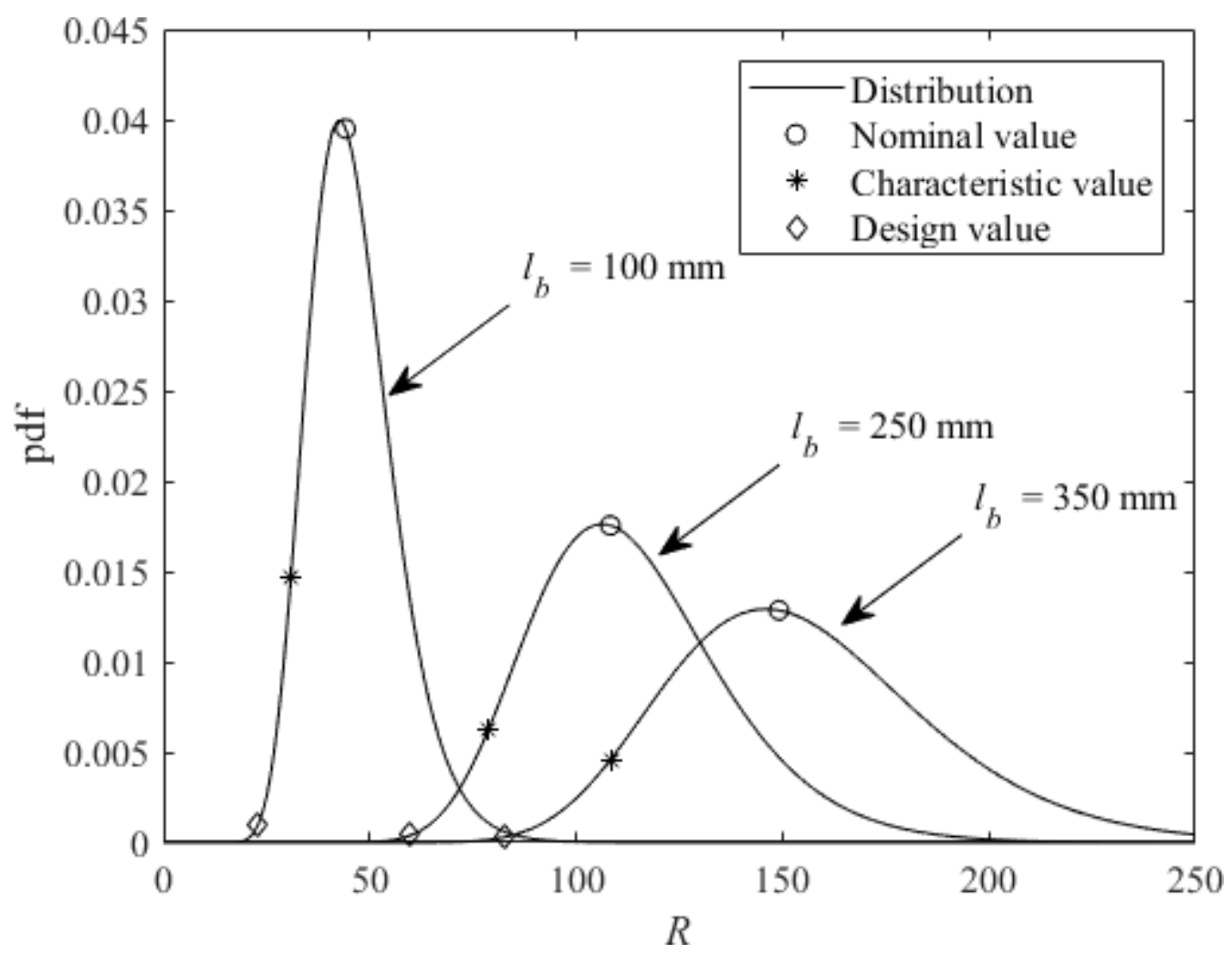

Figure 3: Example of probability distributions for three different embedment lengths, with nominal and design values indicated. The 5\%-fractile characteristic values are also indicated.

Comparative plots have been constructed to study the influence of the basic variables on the partial factors. For each basic variable, the partial factors are divided into two groups depending on the parameter level (lower and upper). These are, in turn, divided into five groups based on the corrosion level. The most interesting plots are presented in Figure 4 and Figure 5, where the partial factors are shown as a circles distributed along the horizontal axes (thus the x-axis refers to the various realisations of the simulations). Note that a difference between the partial factors of the two levels indicates that the basic variable has an influence on $\gamma_{\mathrm{M}}$. A general trend is that higher corrosion level leads to larger $\gamma_{\mathrm{M}}$. In Figure 4 the upper and lower plots differ for corrosion between levels $15 \%$ and $20 \%$. This means that the reinforcement bar diameter (the studied basic variable) has an influence on $\gamma_{\mathrm{M}}$, which is increased for some of the cases with smaller diameter. Figure 5 shows the marked influence of the number of bars anchored in the cross-section. All partial factors deviating from the linear trend have corrosion levels of $15 \%$ or $20 \%$ and belong to the upper parameter level, i.e. $n_{\mathrm{b}}=5$. 

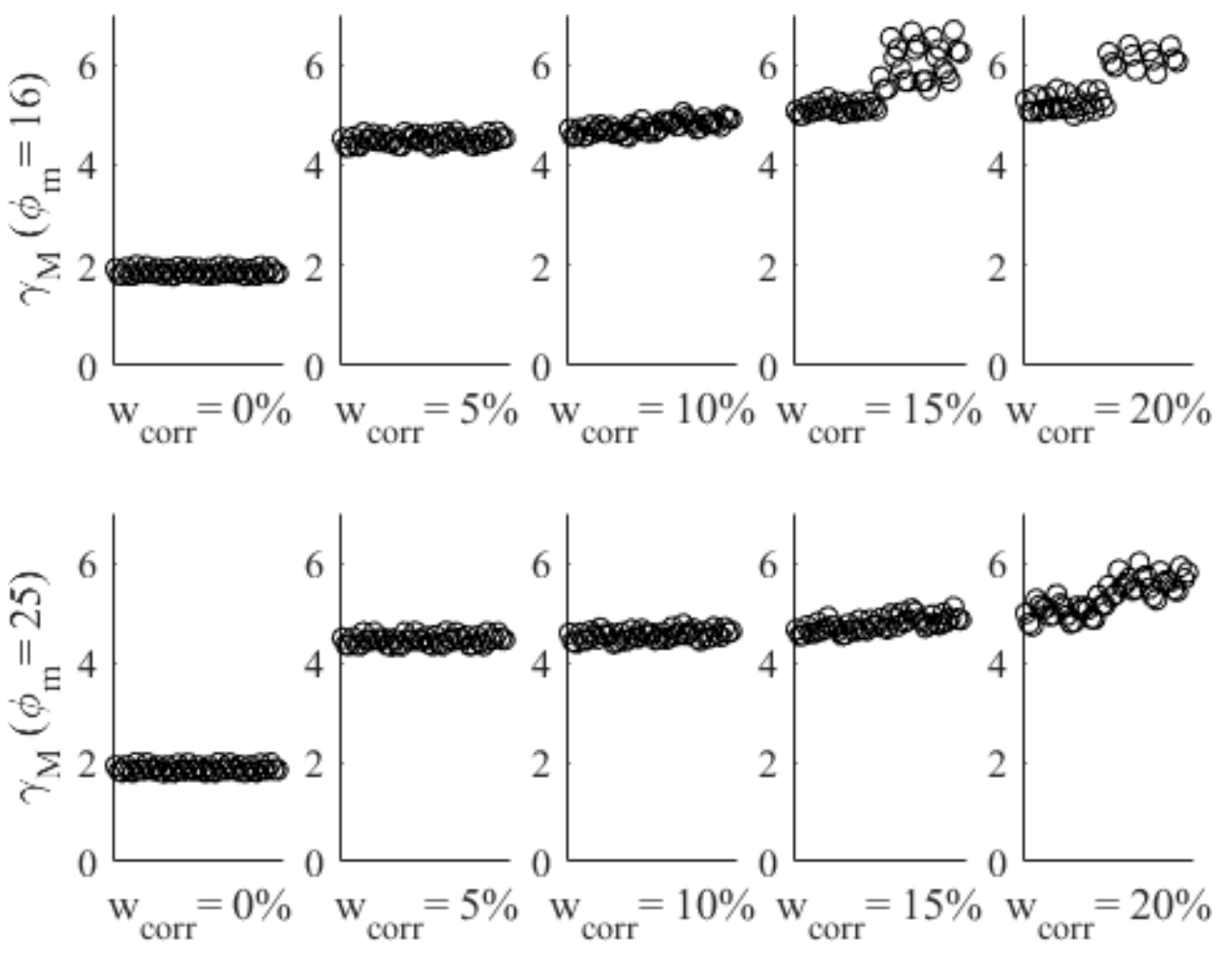

Figure 4: Comparison of partial factors for the two reinforcement bar diameters considered, for cases with stirrups.
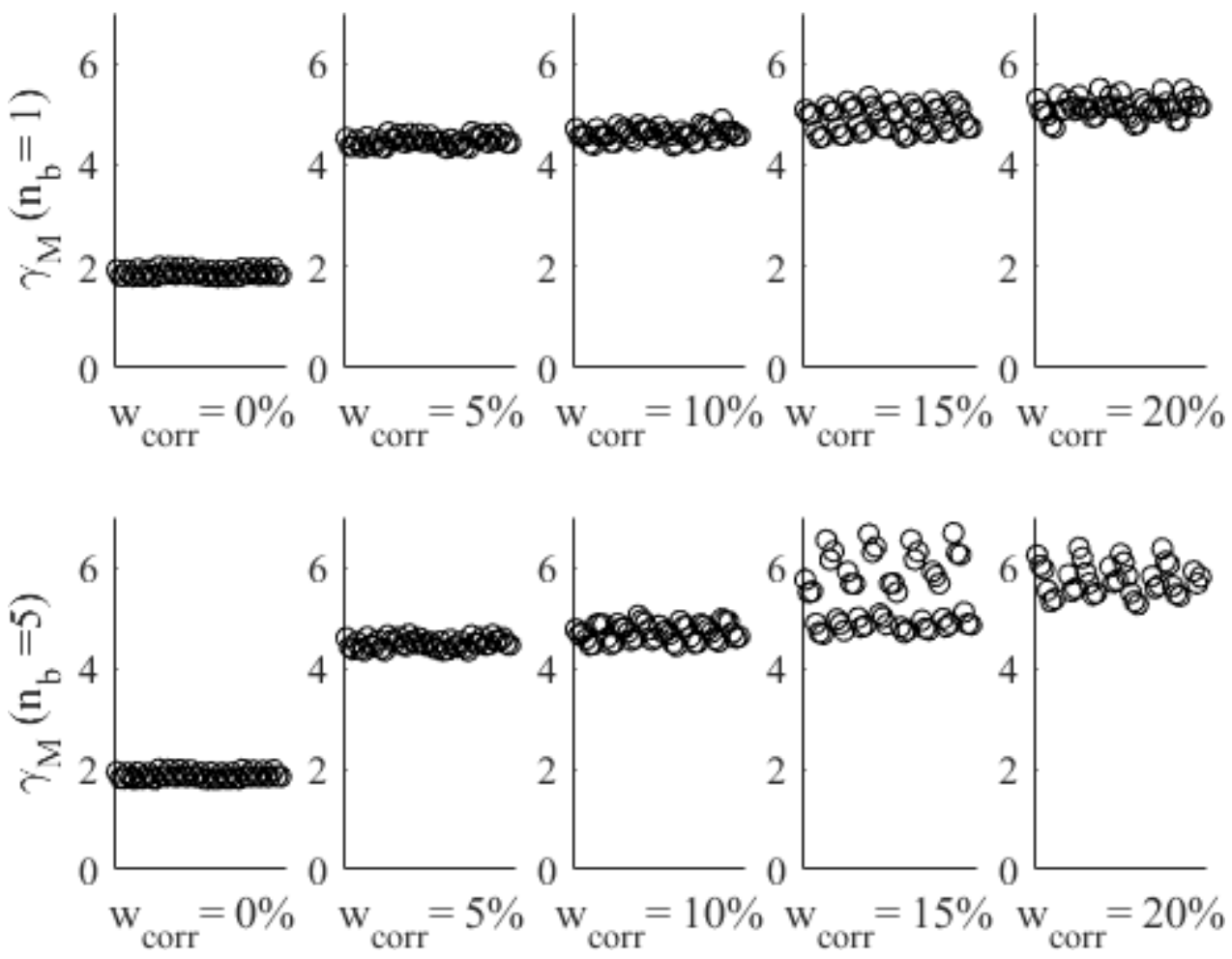

Figure 5: Comparison of partial factors for the two numbers of bars considered, anchored in the cross-section for cases with stirrups. 
The other basic variables presented in Table 6 were studied in plots similar to Figure 4 and Figure 5. For corrosion levels of $15 \%$ or $20 \%$, markedly larger values for $\gamma_{M}$ are apparent than for lower corrosion levels. The common factor in these cases is that they all have $\phi_{\mathrm{m}}=16 \mathrm{~mm}$ and $n_{\mathrm{b}}=$ 5. However, not all design cases with these parameter levels show this difference. The cases which also have the greater spacing between the stirrups $\left(s_{\mathrm{t}}=260 \mathrm{~mm}\right)$ are the ones which show the highest partial factors. Moreover, the shorter embedment length of $100 \mathrm{~mm}$ generally gives a slightly higher partial factor than 250 or $350 \mathrm{~mm}$ embedment length, for all cases. Furthermore, only minor effects from the concrete strength and stirrup efficiency factor were observed.

The derived partial factors for the cases with stirrups are presented in Table 8. For corrosion levels $0 \% 5 \%$ and $10 \%$ these values were chosen near the maximum for the different design cases, however rounded to the nearest 0.1 . For corrosion levels $15 \%$ and $20 \%$ the results were first split in two groups based on the levels of $n_{\mathrm{b}}$, thereafter the same method was applied.

Table 8: Derived partial factors $\gamma_{M}$ for cases with stirrups.

\begin{tabular}{|l|l|}
\hline Corrosion level & \multicolumn{1}{|c|}{$\gamma_{\mathrm{M}}$} \\
\hline $0 \%$ & 1.9 \\
\hline $5 \%$ & 4.7 \\
\hline $10 \%$ & 4.9 \\
\hline $15 \%$ & $5.2-6.4^{*}$ \\
\hline $20 \%$ & $5.2-7.6^{*}$ \\
\hline
\end{tabular}

* Intermediate cases can be interpolated in cases where $n_{\mathrm{b}}$ is $1-5$.

Similar plots were constructed for the partial factors belonging to cases without stirrups and the trends were common to all cases. Figure 6 shows the influence of concrete compressive strength, which is noticeable for $5 \%$ and $10 \%$ corrosion, but minor for the other levels. 

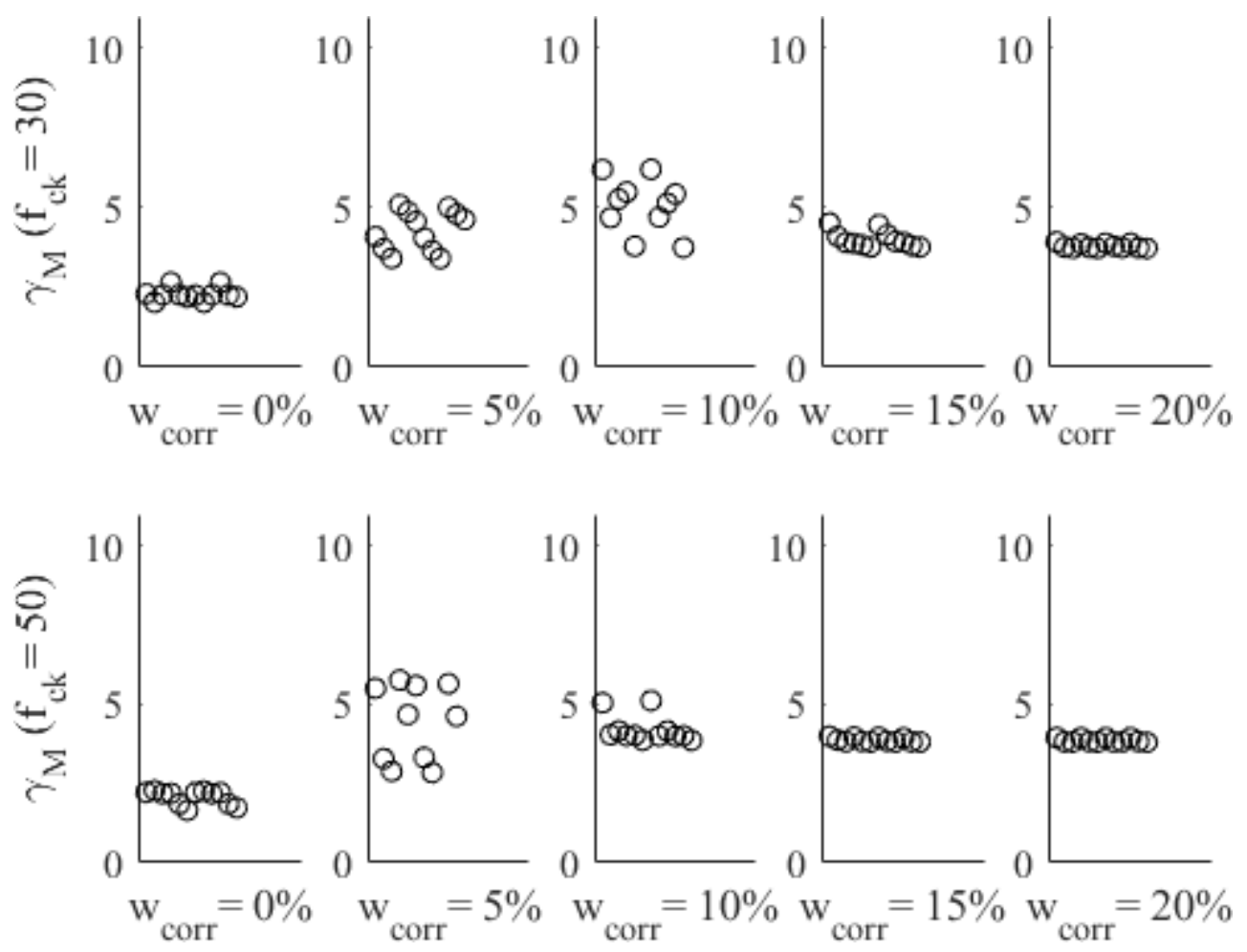

Figure 6: Comparison of partial factors for the two concrete strengths considered, for cases without stirrups.

For two cases with 5\% and 10\% corrosion a lognormal distribution did not represent the resistance well and led to very high partial factors (approx. 20). Furthermore, the reduction in partial factors at the highest corrosion levels can be explained by the bond capacity depending mostly on the residual branch of the bond slip curve, see Figure 2. This, in turn, is solely dependent on the concrete strength and bar diameter. So, despite the corrosion level being greater, its influence on the variability of the bond capacity is less.

Due to the high degree of uncertainty associated with corrosion levels of 5 and $10 \%$ for cases without stirrups, a choice was made not to differentiate between different corrosion levels. The partial factors are derived for an uncorroded case and a corroded case, where the corroded case corresponds to $15 \%$ corrosion. This is the maximum corrosion level validated for cases without stirrups in [15]. Note that this corrosion level should also be used when calculating the nominal value of the resistance. The partial factors for the cases without stirrups were derived similarly to those with stirrups and are presented in Table 9.

Table 9: Derived partial factors $\gamma_{M}$ for cases without stirrups.

\begin{tabular}{|l|l|}
\hline Corrosion level & \multicolumn{1}{|c|}{$\gamma_{\mathrm{M}}$} \\
\hline Uncorroded & 2.0 \\
\hline Corroded & 3.4 \\
\hline
\end{tabular}




\section{VERIFICATION OF PARTIAL FACTORS}

This section presents the method of verifying previously determined partial factors. The procedure for deterministic evaluation of anchorage capacity using partial factors is demonstrated and there then follows a reliability analysis of the results.

\subsection{Deterministic assessment of anchorages and set-up of reliability analyses}

The reliability is studied for cases where the design loads were established using the partial factors summarised in Table 8 and Table 9, for cases with and without stirrups. The end region of a simply supported beam is considered for the reliability analyses. The cross-section of the beam in the end region is shown in Figure 7. The geometrical, material and model parameters are summarised in Table 10-Table 12, while the general input parameters for the ARC model itself were previously presented in Table 2. Some parameters are assigned multiple values (to generate multiple cases); these are the embedment length, number of bars anchored in the cross-section and corrosion level. This results in 20 different cases with stirrups (for consideration in the verification) and four without.

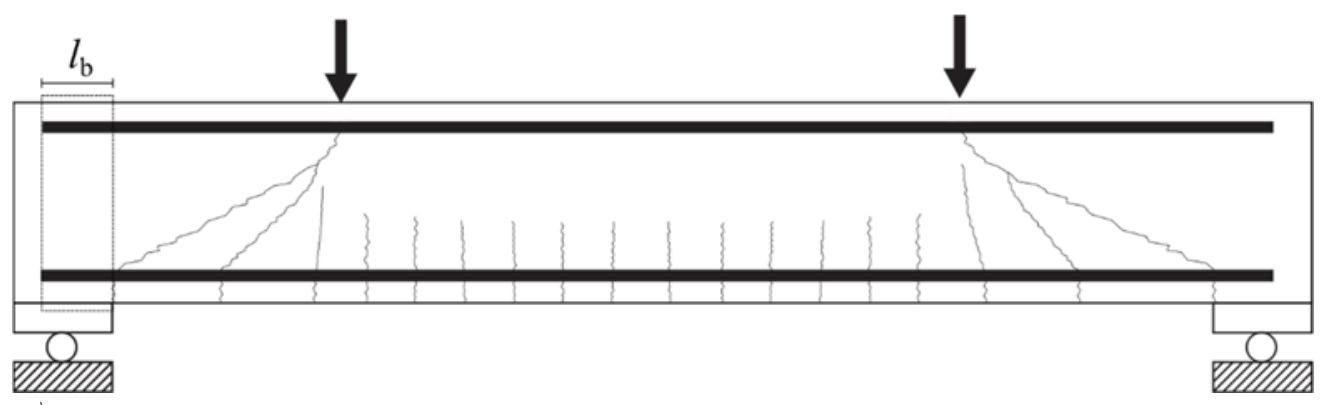

a)

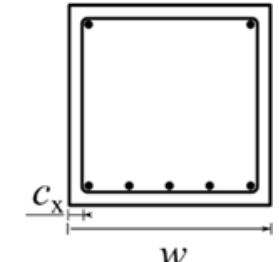

b)

Figure 7: a) side view of beam with the studied cross section and embedment length indicated (not to scale) adopted from [34]. b) cross-section of the beam in the end anchorage region with width and concrete cover indicated.

Table 10: Geometry parameters for beam anchorage assessment and reliability analysis.

\begin{tabular}{|l|l|l|l|l|l|}
\hline \multicolumn{7}{|c|}{ Geometry parameters } \\
\hline Parameter & $\mathbf{X}$ & Dist. & $\mu_{\mathbf{X}}[\mathrm{mm}]$ & $\sigma_{\mathbf{X}}[\mathrm{mm}]$ & $\mathrm{V}[-]$ \\
\hline Beam height & $h$ & Norm. & 400 & 6.4 & 0.02 \\
\hline Beam width & $w$ & Norm. & 400 & 6.4 & 0.02 \\
\hline Main bar dia. & $\phi_{\mathrm{m}}$ & Norm. & 20 & 0.2 & 0.01 \\
\hline Stirrup dia. & $\phi_{\mathrm{s}}$ & Norm. & 10 & 0.1 & 0.01 \\
\hline Stirrup spacing & $S_{\mathrm{t}}$ & Norm. & 260 & 10 & 0.04 \\
\hline X-dir cover & $c_{\mathrm{x}}$ & Gam. & 40 & 10 & 0.25 \\
\hline y-dir cover & $\mathrm{c}_{y}$ & Gam. & 40 & 10 & 0.25 \\
\hline Clear bar spacing & $c_{\mathrm{s}}$ & Gam. & 55 & 10 & 0.18 \\
\hline Clear rib spacing & $c_{\text {clear }}$ & Uni. & $0.45 \phi_{\mathrm{m}}$ & 1.7 & 0.19 \\
\hline $\begin{array}{l}\text { Embedment } \\
\text { length }\end{array}$ & $l_{\mathrm{b}}$ & Norm. & 200,400 & 10 & $0.05,0.03$ \\
\hline
\end{tabular}


Table 11: Material and load parameters for beam anchorage assessment and reliability analysis.

\begin{tabular}{|l|l|l|l|l|l|}
\hline \multicolumn{7}{|c|}{ Material parameters } \\
\hline Parameter & $\mathbf{X}$ & Dist. & $\mu_{\mathbf{X}}[\mathrm{MPa}]$ & $\sigma_{\mathbf{X}}[\mathrm{MPa}]$ & $\mathrm{V}[-]$ \\
\hline Concrete strength & $f_{\mathrm{cm}}$ & Logn. & 38 & 6.35 & 0.17 \\
\hline Steel strength & $f_{\mathrm{y}}$ & Logn. & 560 & 30 & 0.05 \\
\hline Steel E-modulus & $E_{\mathrm{s}}$ & Det. & 200,000 & - & \\
\hline
\end{tabular}

Table 12: Model parameters for beam assessment and reliability analysis.

\begin{tabular}{|l|l|l|l|l|l|l|}
\hline \multicolumn{7}{|c|}{ Model parameters } \\
\hline Parameter & $\mathbf{X}$ & Dist. & $\mu_{\mathbf{X}}[-]$ & $\sigma_{\mathbf{X}}$ & V [-] & Ref. \\
\hline $\begin{array}{l}\text { Model uncertainty for the } \\
\text { permanent load }\end{array}$ & $\theta_{\mathrm{Ed}, \mathrm{G}}$ & Normal & 1 & 0.07 & 0.07 & {$[28]$} \\
\hline $\begin{array}{l}\text { Model uncertainty for the } \\
\text { variable load }\end{array}$ & $\theta_{\mathrm{Ed}, \mathrm{Q}}$ & Normal & 1 & 0.11 & 0.11 & {$[28]$} \\
\hline Permanent load & $g$ & Norm. & - & - & 0.10 & {$[28]$} \\
\hline Variable load & $q$ & $\begin{array}{l}\text { Gum. } \\
(\max )\end{array}$ & - & - & 0.25 & {$[28]$} \\
\hline Number of anchored bars & $n \mathrm{~b}$ & Det. & 1,5 & - & & \\
\hline Stirrup legs crossed by cracks & $n_{\mathrm{t}}$ & Det. & 1 & - & & \\
\hline Effectiveness of stirrups & $k_{\mathrm{m}}$ & Det. & $\begin{array}{l}12 / 0 \quad \text { for } \\
\text { corner/interior } \\
\text { bar }\end{array}$ & - & & \\
\hline
\end{tabular}

First, the deterministic capacities for each case were calculated using the characteristic material strengths and nominal values for the other basic variables. In cases with a single bar it was assumed to be in the centre of the cross-section, and effectiveness factor of the stirrups $\left(k_{\mathrm{m}}=0\right)$. For the cases with all five bars anchored in the cross-section, the anchorage force was averaged between the four outer bars $\left(k_{\mathrm{m}}=12\right)$ and the interior bar $\left(k_{\mathrm{m}}=0\right)$. For the cases without stirrups, it is only necessary to consider one anchored bar, as anchoring five bars in the crosssection gives the same capacity per bar. Furthermore, as only the cross-section is studied and not the entire structure, the influence of transverse support pressure on the local bond-slip relationship is conservatively neglected. The anchored forces were then divided by the pertinent partial factor from Table 8 and Table 9, to obtain the design value of the resistance.

For the reliability analyses, the design load was set as equal to the design resistance for each case: $F_{\mathrm{Rd}}=E_{\mathrm{d}}$. The permanent and imposed variable load portions of the total load were calculated based on the design loads. The factor $\chi$ is used to describe the relation between the characteristic levels of the permanent and imposed variable load, where $\chi=q_{\mathrm{k}} /\left(g_{\mathrm{k}}+q_{\mathrm{k}}\right)$. Using the Adjusted Partial Factor Method suggested in [28] and the selected one-year target reliability index from Section 3.2, the load partial factors $\gamma_{\mathrm{G}}=1.35$ and $\gamma_{\mathrm{Q}}=0.90$ were obtained for the permanent 
and imposed variable loads respectively. Based on [35] a 5-year basic reference period was assumed for the variable load. Note that according to [28], $q_{\mathrm{k}}$ is the intensity of the imposed variable load with a $5 \%$ exceedance probability over a reference period of 50 years, resulting in $\gamma_{\mathrm{Q}}<1.0$ since $\gamma_{\mathrm{Q}}$ takes into account both the reduced target reliability index and the shorter reference period. The characteristic loads can then be determined according to:

$$
q_{\mathrm{k}}=\frac{F_{\mathrm{Rd}}}{1.35\left(\frac{1}{\chi}-1\right)+0.90}, \quad g_{\mathrm{k}}=q_{\mathrm{k}}\left(\frac{1}{\chi}-1\right)
$$

In the reliability analyses presented here, $\chi=0.5$ and the characteristic load levels are taken as $50 \%$-fractile for the permanent load and $95 \%$-fractile for the variable load. The loads are modelled according to Table 12. The parameters for the one-year distribution of the variable load corresponding to $q_{\mathrm{k}}$ for each case can be derived using the expressions describing the Gumbel distribution.

\subsection{Reliability verification of anchorages assessed using partial factors}

The reliability analyses were performed in MATLAB release 2016a [31] using the software framework UQlab [32]. The reliability was quantified using a first order reliability method (FORM) [36] analysis with subsequent importance sampling simulations [32]. The convergence criterion was established by setting the target $\mathrm{V}$ for $\beta$ to 0.05 .

The verified cases, applied partial factors, design resistances, plus the resulting reliability indices and their confidence intervals (CI) are presented in Table 13 and Table 14, for cases with and without stirrups respectively. The results in reliability indices are also plotted against the corrosion level in Figure 8.

Table 13: Summary of verified cases with stirrups.

\begin{tabular}{|l|l|l|l|l|l|l|l|}
\hline Case & $n_{\mathrm{b}}$ & $l_{\mathrm{b}}\left(\mu_{\mathrm{x}}[\mathrm{mm}]\right)$ & $w_{\text {corr }}\left(\mu_{\mathbf{x}}\right)$ & $\gamma_{\mathrm{M}, \text { stir }}[-]$ & $\mathrm{F}_{\mathrm{Rd}, \mathrm{stir}}[\mathrm{kN}]$ & $\beta$ & $\beta 95 \% \mathrm{CI}$ \\
\hline 1 & 1 & 200 & $0 \%$ & 1.9 & 52.3 & 4.6 & $4.61-4.65$ \\
\hline 2 & 1 & 200 & $5 \%$ & 4.7 & 16.7 & 4.3 & $4.27-4.31$ \\
\hline 3 & 1 & 200 & $10 \%$ & 4.9 & 13.6 & 4.3 & $4.27-4.31$ \\
\hline 4 & 1 & 200 & $15 \%$ & 5.2 & 11.0 & 4.1 & $4.11-4.15$ \\
\hline 5 & 1 & 200 & $20 \%$ & 5.2 & 9.0 & 4.0 & $3.93-3.98$ \\
\hline 6 & 1 & 400 & $0 \%$ & 1.9 & 102.5 & 4.7 & $4.66-4.70$ \\
\hline 7 & 1 & 400 & $5 \%$ & 4.7 & 32.5 & 4.3 & $4.28-4.32$ \\
\hline 8 & 1 & 400 & $10 \%$ & 4.9 & 26.9 & 4.3 & $4.27-4.31$ \\
\hline 9 & 1 & 400 & $15 \%$ & 5.2 & 21.4 & 4.1 & $4.09-4.14$ \\
\hline 10 & 1 & 400 & $20 \%$ & 5.2 & 17.5 & 4.0 & $3.97-4.02$ \\
\hline 11 & 5 & 200 & $0 \%$ & 1.9 & 53.5 & 4.6 & $4.61-4.65$ \\
\hline 12 & 5 & 200 & $5 \%$ & 4.7 & 16.8 & 4.2 & $4.22-4.26$ \\
\hline 13 & 5 & 200 & $10 \%$ & 4.7 & 13.3 & 4.2 & $4.18-4.23$ \\
\hline 14 & 5 & 200 & $15 \%$ & 6.4 & 8.3 & 3.9 & $3.92-3.97$ \\
\hline
\end{tabular}




\begin{tabular}{|l|l|l|l|l|l|l|l|}
\hline 15 & 5 & 200 & $20 \%$ & 7.6 & 5.4 & 4.0 & $3.98-4.03$ \\
\hline 16 & 5 & 400 & $0 \%$ & 1.9 & 105.0 & 4.7 & $4.67-4.71$ \\
\hline 17 & 5 & 400 & $5 \%$ & 4.7 & 32.5 & 4.3 & $4.27-4.31$ \\
\hline 18 & 5 & 400 & $10 \%$ & 4.7 & 26.0 & 4.2 & $4.16-4.20$ \\
\hline 19 & 5 & 400 & $15 \%$ & 6.4 & 16.2 & 4.0 & $3.94-3.99$ \\
\hline 20 & 5 & 400 & $20 \%$ & 7.6 & 10.7 & 4.0 & $3.99-4.03$ \\
\hline
\end{tabular}

Table 14: Summary of verified cases without stirrups.

\begin{tabular}{|c|c|c|c|c|c|c|}
\hline Case & $\begin{array}{c}l_{\mathrm{b}}\left(\mu_{\mathrm{X}}\right. \\
[\mathrm{mm}])\end{array}$ & $\begin{array}{c}w_{\text {corr }} \\
\left.\mu_{\mathbf{X}}\right)\end{array}$ & $\begin{array}{c}\gamma_{\mathrm{M}, \text { nostir }} \\
{[-]}\end{array}$ & $\begin{array}{c}\mathrm{F}_{\mathrm{Rd}, \text { nostir }} \\
{[\mathrm{kN}]}\end{array}$ & $\beta$ & $\beta 95 \% \mathrm{CI}$ \\
\hline 1 & 200 & $0 \%$ & 2.0 & 37.1 & 4.6 & $4.53-4.61$ \\
\hline 2 & 200 & $15 \%$ & 3.4 & 3.9 & 3.9 & $3.89-3.98$ \\
\hline 3 & 400 & $0 \%$ & 2.0 & 57.7 & 3.9 & $3.90-4.00$ \\
\hline 4 & 400 & $15 \%$ & 3.4 & 7.7 & 3.9 & $3.89-3.98$ \\
\hline
\end{tabular}

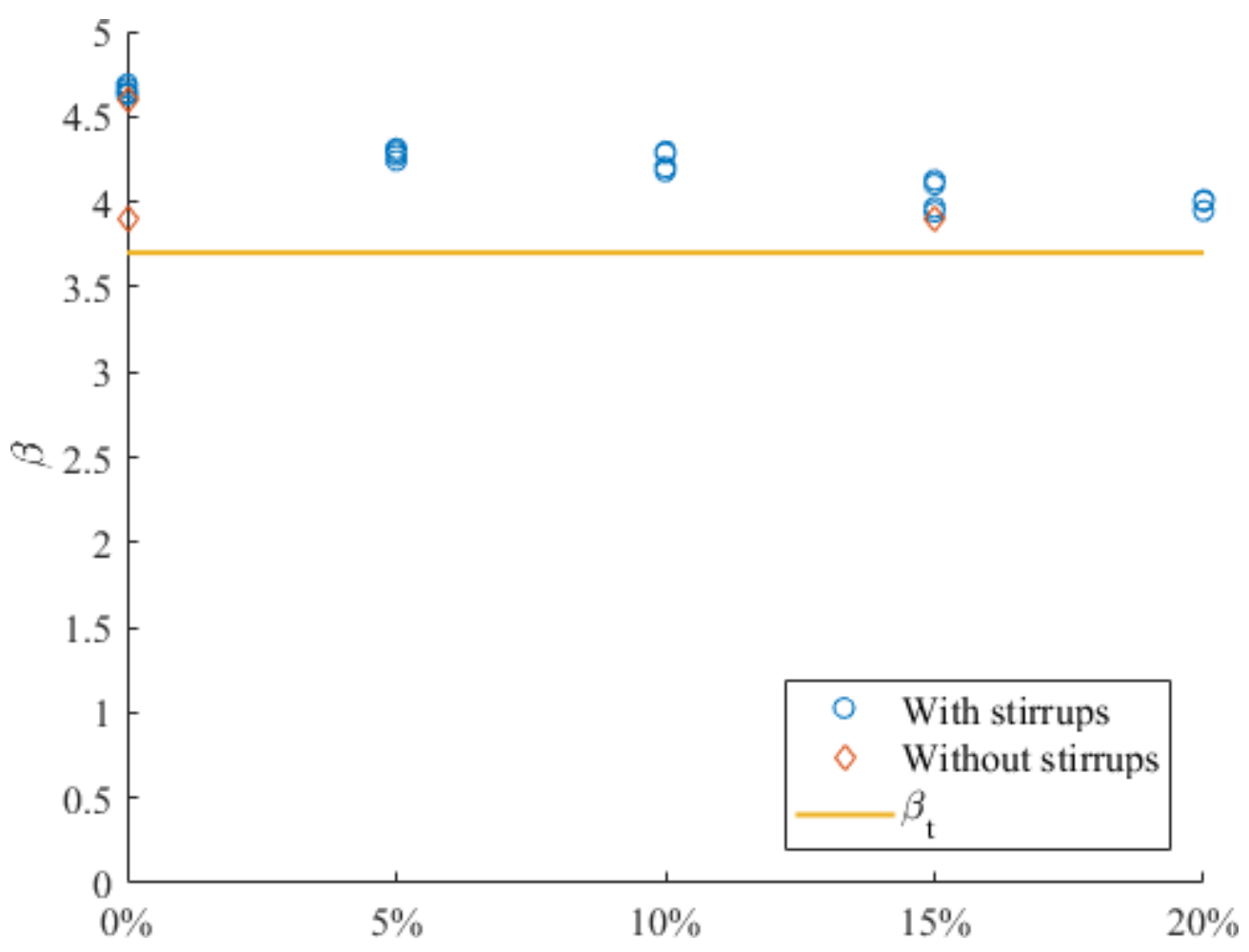

Figure 8: Reliability indices obtained from the verification for cases with and without stirrups, plotted against the corrosion level. The target reliability is indicated with a line.

It can be seen that reliability indices greater than the target are achieved for all cases, with or without stirrups. For uncorroded cases and lesser corrosion levels, the reliability indices are well above target level. However, the margin is lower for the greatest corrosion levels. Furthermore, the derived partial factors were compared to Eurocode provisions for an uncorroded case. For the 
beam presented in [29], the ARC2010 model together with the derived partial factor gives a slightly shorter required anchorage length compared to Eurocode.

The influence of the basic variables on reliability is shown in Figure 9, using squared sensitivity factors $\alpha^{2}$ obtained from FORM analyses. The uncorroded case is presented along with three different corrosion levels of $5 \%, 10 \%$ and $15 \%$. Small sensitivity factors $(<0.02)$ have been added together and appear as "Other". For uncorroded cases, it is apparent that the most influential basic variables are the modelling uncertainty and variable load. When corrosion is increased to $5 \%$, the resistance model uncertainty contributes the largest $\alpha^{2}$, as the model uncertainty is markedly increased compared to the uncorroded case (see Table 2). With increasing corrosion level, the corrosion level gains a greater sensitivity factor. The influence of $c_{\text {clear }}$ is also increased with increasing corrosion. This is expected, considering its part in the mechanical model.

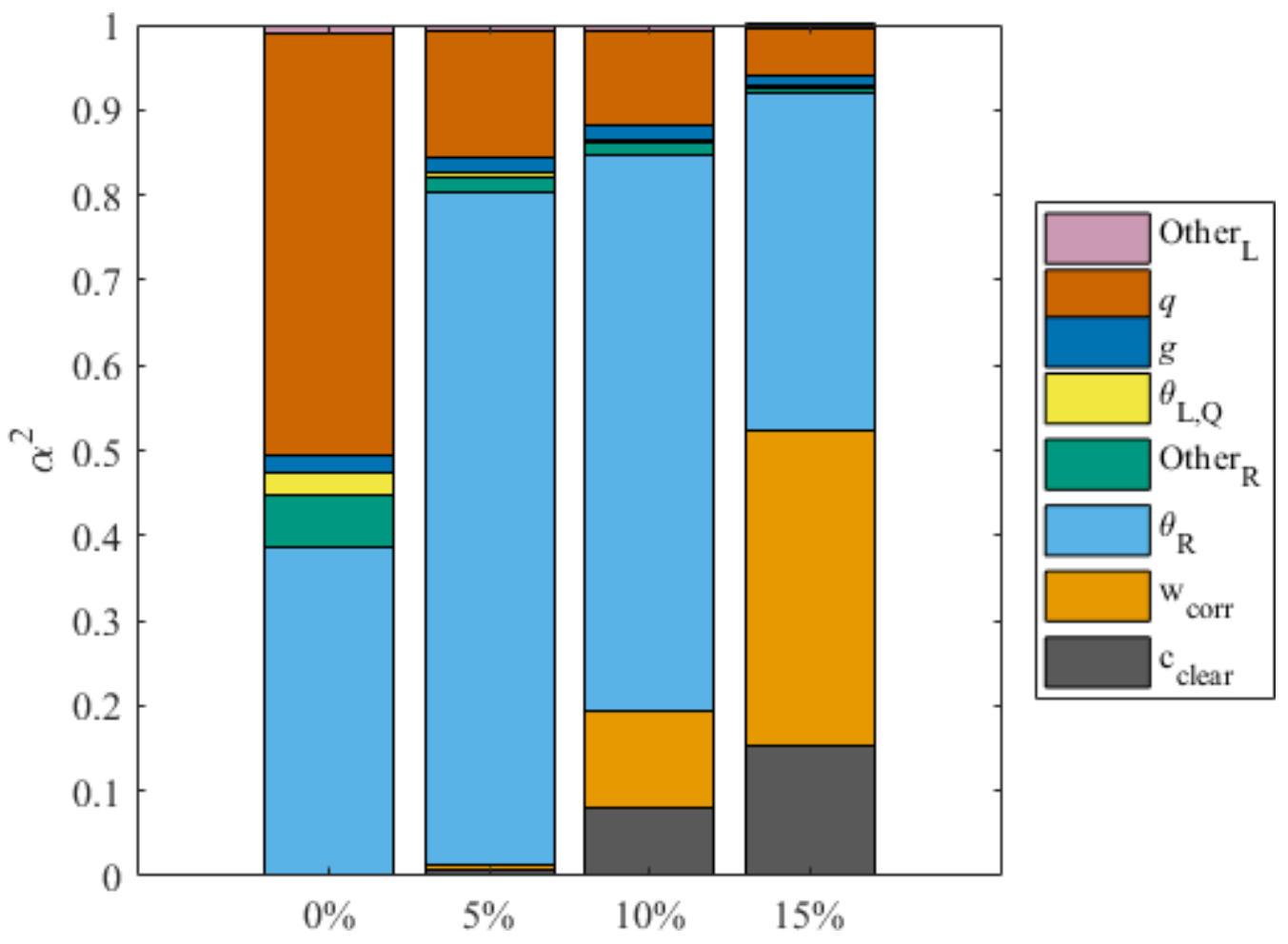

Figure 9: Graphical illustration of representative FORM sensitivity factors for cases with stirrups.

For uncorroded cases without stirrups, the resistance model uncertainty contributes around 50\%, and the remaining part is mainly due to variable load. For corroded cases, the model uncertainty makes up over $90 \%$ of the total sensitivity, with the rest being mainly live load. 


\section{DISCUSSION}

Figure 8 shows that the reliability indices are reduced as the corrosion level increases. For uncorroded cases, the reliability is well above target, while for $20 \%$ corrosion it is slightly above. The sensitivity factor for the resistance $\alpha_{\mathrm{R}}$ was taken as 0.8 in the calibration of the partial factors according to standard practice, corresponding to a squared value of 0.64 in Figure 9. This value corresponds fairly well to the results for uncorroded cases, but it is less than the actual sensitivity of the resistance parameters for cases with corrosion. This may be the reason for the reduction in reliability index with increasing corrosion level as, according to Equation 11, a greater actual sensitivity for the resistance parameters would yield a higher partial factor.

The chosen partial factors for the loads may also influence the results and may be the reason for the difference between the target and actual reliability indices for uncorroded cases. In particular, the factor for self-weight was set at a large value in line with Eurocode recommendations. The characteristic load levels in the verification procedure are derived based on the design loads in Equation 15 and high partial factors lead to low characteristic values. As the partial factors in Eurocode are only valid for a specific situation (and might not be representative of the present case), the characteristic load levels considered in the reliability analysis might be a bit low. This is reflected in the higher reliability index. However, the influence of the loads is reduced with increasing corrosion level and the effect is less pronounced.

It is clear from the sensitivities presented in Figure 9 that the resistance model uncertainty has a major influence in the probabilistic model and therefore also on the derived partial factors. The modelling uncertainty derived in Section 2.3 is large, but not markedly different from that associated with other models presented in [28]. To reduce the overall uncertainty of anchorage capacity predictions for corroded reinforcement (and thereby the values of the partial factors required to ensure sufficient safety), it would largely beneficial to reduce the modelling uncertainty. Further research into this is therefore proposed.

The results presented in Figure 9 also highlight the importance of the corrosion level in the reliability analyses. At the same time, accurate estimation of the corrosion level is difficult to obtain from non-destructive testing on existing structures. It is possible to quantify based on measurements of crack widths [37], but the results in the literature are scattered. An understanding can also be formed if the corrosion rate is monitored using, say, an electrochemical technique [38], with additional assumptions regarding the onset time of corrosion and previous corrosion rate. One approach to obtaining a more realistic representation of the uncertainty in the corrosion level for in-situ structures would be to link it to the assessment method. This is because different methods are likely to show differing accuracy in quantification. However, it should be kept in mind that the corrosion level is likely to vary over the length of the reinforcement bars and, depending on the embedment length being considered, the average value would differ. It is therefore no small matter to find a reasonable probability distribution for the corrosion level and 
dedicated work towards this goal, and towards bond models that make use of this information, is proposed as an avenue for further work.

It should be emphasised that the partial factors derived in the paper are based on several assumptions and applicable to a specific problem, namely the anchorage failure of corroded reinforcement only. The user of the ARC2010 model must be aware of its limitations and accept responsibility of the resulting decisions. However, the procedure presented here for deriving the partial factors is a general one. It may be followed in order to derive partial factors based on other assumptions and on other mechanical models.

\section{CONCLUSIONS}

The main conclusions that can be drawn based on the results presented are:

- Partial factors leading to a target safety level can be derived for anchorage capacity of corroded reinforcement bars.

- The partial factors lead to a reliability index exceeding the target for all situations for the case studied and verify the safety level.

- Modelling uncertainty is highly influential on anchorage capacity of reinforcement, especially in the case of corrosion.

- Further research is needed, to quantify reasonable levels for the sensitivity factors of the basic variables in deteriorated concrete structures.

\section{ACKNOWLEDGEMENTS}

The funding from the Swedish Transport Administration, RISE CBI Swedish Cement and Concrete Research Institute's A-consortium and SBUF is appreciated and acknowledged. Associate Professor Kamyab Zandi and Professor Karin Lundgren at Chalmers University of Technology are recognised for their contributions in discussions regarding the work presented here.

\section{REFERENCES}

[1] B. Bell, D1.3 European Railway Bridge Problems, sustainablebridges.net, 2004.

[2] BRIME, "Bridge management in Europe, research project no.: RO-97-SC.2220, The European union: transport research and technological development.," 2001.

[3] X. Xi and S. T. Yang, "Time to surface cracking and crack width of reinforced concrete structures under corrosion of multiple rebars," Construction and Building Materials, vol. 
155, p. 114-125, 2017.

[4] I. Sæther, "Bond deterioration of corroded steel bars in concrete," Structure and Infrastructure Engineering, vol. 7, no. 6, pp. 415-429, 2011.

[5] A. Almusallam, . A. Al-Gahtani, A. Aziz and A. Rasheeduzzafar, "Effects of reinforcement corrosion on bond strength," Construction and Building Materials, vol. 10, no. 2, pp. 123129, 1996.

[6] Y. Auyeung, . P. Balaguru and L. Chung, "Bond behavior of corroded reinforcement bars," ACI Structural Journal, vol. 97, no. 2, pp. 214-220, 2000.

[7] G. Al-Sulaimani, M. Kaleemullah, I. Basunnul and A. Rasheeduzzafar, "Influence of corrosion and cracking on bond behaviour and strength of reinforced concrete members," ACI Structural Journal, vol. 97, no. 2, pp. 220-231, 1990.

[8] J. Rodriguez, L. Ortega and J. Casal, "Load carrying capacity of concrete structures with corroded reinforcement," Construction and Building Materials, vol. 11, no. 4, pp. 239-248, 1997.

[9] P. Mangat and M. Elgarf, "Bond characteristics of corroding reinforcement in concrete beams," Materials and Structures, vol. 32, no. 2, pp. 89-97, 1999.

[10] J. Cairns, Y. Du and D. Law, "Structural performance of corrosion-damaged concrete beams," Magazine of Concrete Research, vol. 60, no. 5, pp. 359-370, 2008.

[11] K. Lundgren, P. Kettil, K. Zandi Hanjari, H. Schlune and A. Soto San Roman, "Analytical model for the bond-slip behaviour of corroded ribbed reinforcement," Structure \& Infrastructure Engineering, vol. 8, no. 2, pp. 157-169, 2012.

[12] K. Zandi, "Corrosion-induced cover spalling and anchorage capacity," Structure and Infrastructure Engineering, vol. 11, no. 12, pp. 1-18, 2015.

[13] K. Lundgren, "Bond between ribbed bars and concrete. Part 2: The effect of corrosion," Magazine of Concrete Research, vol. 57, no. 7, pp. 383-395, 2005.

[14] C. Li, S. Yang and M. Saafi, "Numerical Simulation of Behavior of Reinforced Concrete Structures considering Corrosion Effects on Bonding," Journal of Structural Engineering, vol. 140, no. 12, pp. 1-10, 2014.

[15] M. Blomfors, K. Zandi, K. Lundgren and D. Coronelli, "Engineering bond model for corroded reinforcement," Engineering structures, vol. 156C, pp. 394-410, 2018. 
[16] CEB, "EN 1990: Eurocode - Basis of structural design," European Committee for Standardization, Brussels, 2002.

[17] G. Mancini, V. I. Carbone, G. Bertagnoli and D. Gino, "Reliability-based evaluation of bond strength for tensed lapped joints and anchorages in new and existing reinforced concrete structures," Structural Concrete, vol. 19, no. 3, pp. 904-917, 2017.

[18] JCSS (Joint Committee on Structural Safety), Probabilistic model code, Zurich: JCSS, 2001.

[19] fib, "Chapter 6: Interface characteristics," in fib Model Code for Concrete Structures 2010, Lausanne, fib, 2013, pp. 152-189.

[20] M. Engen, . M. Hendriks, J. Köhler, J. Øverli and E. Åldstedt, "A quantification of the modelling uncertainty of non-linear finite element analyses of large concrete structures," Structural Safety, vol. 64, pp. 1-8, 2017.

[21] H. Lilliefors, "On the Kolmogorov-Smirnov test for normality with mean and variance unknown," Journal of the American Statistical Association, vol. 62, pp. 399-402, 1967.

[22] A. Gelman, J. Carlin, H. Stern, D. Dunson, A. Vehtari and D. Rubin, Bayesian data analysis, 3rd ed., Boca Raton: CRC Press, 2014.

[23] M. Holický, "Annex A - Basic statistical concepts and techniques," in Implementation of Eurocodes: Handbook 2 - Reliability backgrounds, Prague, 2005.

[24] SIS, SS-EN 10080: Steel for the reinforcement of concrete - Weldable reinforcing steel General, Swedish Standard, 2005.

[25] M. Engen, M. Hendriks, J. Köhler, J. Øverli, E. Åldstedt, E. Mørtsell, Ø. Sæter and R. Vigre, "Predictive strength of ready-mixed concrete: Exemplified using data from the Norwegian market," Structural Concrete, pp. 1-14, 2017.

[26] CEN, "EN 1990: Eurocode - Basis of structural design," European Committee for Standardization, Brussels, 2002.

[27] CEN, "EN 1992-1-1 Eurocode 2: Design of concrete structures - Part 1-1: General rules and rules for buildings," European Committee for Standardization, Brussels, 2005.

[28] fib, fib bulletin 80. Partial factors for existing concrete structures, Lausanne: fib, 2016.

[29] M. Blomfors, K. Zandi, O. Larsson Ivanov, D. Honfí and K. Lundgren, "Reliability Analysis of Corroded Reinforced Concrete Beam with regards to Anchorage Failure," in The sixt 
international symposium on Life-Cycle Civil Engineering 2018, Ghent, 2018.

[30] C. Graham and D. Talay, Stochastic simulation and monte carlo methods, Berlin: Springer, 2013.

[31] The Mathworks Inc., MATLAB R2016a, 2016.

[32] S. Marelli, R. Schöbi and B. Sudret, "UQLab user manual - Structural Reliability, Report UQLab-V1.0-107,” Chair of Risk, Safety \& Uncertainty Quantification, Zurich, 2017.

[33] M. McKay, R. Beckman and W. Conover, "Comparison of Three Methods for Selecting Values," Technometrics, vol. 21, no. 2, pp. 239-245, 1979.

[34] D. Coronelli, K. Zandi and K. Lundgren, "Severely Corroded RC with Cover Cracking," Journal of Structural Engineering, vol. 139, no. 2, pp. 221-232, 2013.

[35] R. Caspeele, M. Sykora, D. Allaix and R. Steenbergen, "The design value method and Adjusted Partial Factor Approach for existing structures," Structural Engineering International: Journal of the International Association for Bridge and Structural Engineering (IABSE), vol. 23, no. 4, pp. 386-393, 2013.

[36] O. Ditlevsen and H. Madsen, Structural reliability methods, Chichester: Wiley, 2005.

[37] M. Tahershamsi, I. Fernandez, K. Lundgren and K. Zandi, "Investigating correlations between crack width, corrosion level and anchorage capacity," Structure and Infrastructure Engineering, vol. 13, no. 10, pp. 1294-1307, 2017.

[38] C. Andrade and C. Alonso, "Test methods for on-site corrosion rate measurement of steel reinforcement in concrete by means of the polarization resistance method," Materials and Structures, vol. 37, no. 9, pp. 623-643, 2004. 